The Social Sciences 7 (2): 308-315, 2012

ISSN: $1818-5800$

(C) Medwell Journals, 2012

\title{
The Multiple Intelligences Integrated Learning of Environmental Education to Promote Knowledge, Attitude and Awareness about Environmental Conservation of Chiang Mai Rajabhat University Students
}

\author{
Phannikar Utthawang, Prayoon Wongchantra and Prasat Neungchalerm \\ Department of Environmental Education, Faculty of Environmental and Resource Studies, \\ Mahasarakham University, 44150 Mahasarakham, Thailand
}

\begin{abstract}
The degree of violence concerning the environmental problem has currently been increased. Many academics have provided several ideas about causes of the problem. However, they often suggest that the environmental problem comes from humans who always think that they are supernatural. With this reason, they all agreed to conclude that the environmental problem must be solved with humans. The use of the environmental education principles together with both formal and non-formal education will be a mean to help bring the environment back to its normal condition. The purposes of this research were: to investigate the effectiveness index of multiple intelligences integrated learning plans; to study and compare the knowledge, attitude and awareness about environmental conservation of students before and after the use of multiple intelligences integrated learning and the normal learning and to study and compare the knowledge, attitude and awareness about environmental conservation of students classified by genders, programs of study and learning methods. The sample used in this research was 60 full time bachelor degree students of all years of study of Chiang Mai Rajabhat University who enrolled to study the course of Humans and Sustainable Environment. They were divided into 2 groups: experimental and controlled groups and were selected by cluster random sampling by drawing. The instruments used for data collection were 2 sets of learning plans, a test of knowledge about environmental conservation, a test of attitude toward environmental conservation and a test for the awareness toward environmental conservation. The first set of multiple intelligences integrated learning plans was used with the experimental group. The second set of normal learning plans was used with the controlled group. The test of knowledge about environmental conservation had 40 items with the difficulty between 0.20 and 0.80 , the discrimination between 0.27 and 62 and the reliability for the whole study of 0.87 . The test of attitude toward environmental conservation had 20 items. The test of awareness toward environmental conservation had 70 items with 5-rating scale, the discrimination between. About 0.20 and 91 and the reliability for the whole study of 0.98 . The data was statistically analyzed by using mean, percentage, standard deviation, $t$ and F-test (three-way MANOVA). The research results were as follows: The effectiveness index of multiple intelligences integrated learning plans was 0.7463 . This finding indicated that the learning progress of students was at $74.63 \%$. The levels of knowledge, attitude and awareness about environmental conservation of the students in general after the use of multiple intelligences integrated learning and normal learning were higher than those before the learning with statistical significance at a level of 0.05 . The levels of knowledge, attitude and awareness about environmental conservation of the students with different genders and programs of study after the learning were not different. The levels of knowledge, attitude and awareness about environmental conservation of the students with different learning methods were different with statistical significance at a level of 0.05 . The knowledge, attitude and awareness about the environmental conservation of the students with multiple intelligences integrated learning were higher than those of students with normal learning with statistically significance. There was no relationship among genders, programs of study and learning methods with the knowledge, attitude and awareness about environmental conservation of the students in general after the use of multiple intelligences integrated learning and normal learning were higher than those before the learning with statistical significance at a level of 0.05 . The levels of knowledge, attitude and awareness about environmental conservation of the students with different genders and programs of study after the learning were not different. The levels of knowledge, attitude and awareness about environmental conservation of the students with different learning methods were different with statistical significance at a level of 0.05 . The qknowledge, attitude and awareness about the environmental conservation of the students with multiple
\end{abstract}

Corresponding Author: Phannikar Utthawang, Faculty of Environmental and Resource Studies, Mahasarakham University, 44150 Mahasarakham, Thailand 
intelligences integrated learning were higher than those of students with normal learning with statistically significance. There was no relationship among genders, programs of study and learning methods with the knowledge, attitude and awareness about environmental conservation.

Key words: Integrated learning, multiple intelligences, environmental education, learning methods, environmental conservation, knowledge

\section{INTRODUCTION}

The problems about deteriorated environment and ecological system have been the problems of people around the world. Thailand is one of the countries in the world that will get impacts from the environmental problems both inside and outside the country. There have been more alertness and awareness about the involvement in solving and protecting the environmental problems. Regarding the education, its role is to produce qualified population of the country. When considering the principles, education is to provide the growths of personal intelligence, thought, mind and moral. As humans are part of the nature, they have to live happily together with it through mutual reliance. Humans have to aware about the use and conservation of natural resources appropriately and do not destroy the environment. The advancement of modern sciences and the acceptance of other culture from outside the country or the community must be considered together with the understanding and awareness about the value of intelligence, language and original culture of a local community and Thai society. This approach will benefit the development of new knowledge in relation to the conditions and needs of local communities.

From an urgent need to solve the environmental problems occurring, all parts that are responsible for the matter and many academics have agreed that the use of environmental education process will be the way leading to sustainable solutions for the problems. The environmental education is a systematic process to provide knowledge about the environment. It focuses on proving people in general awareness toward value of the environment (Chunkao, 1993; Veerawattananon, 2003). Bringing the environmental education process into practice in solving the environmental problems, it is very important for the educational management to provide learners the knowledge, understanding and awareness about value of the environment. It is also important that those who provide knowledge of the environment must think about methods or forms of learning that provide the learners with ways to protect and converse the environment. When the problems occur, these people together will be ready to get involved in solving them. An integrated learning is a form of learning that helps the learners understand the contents in a holistic way. The learners can quickly see a relationship of the information. This form of learning will motivate and provide them with knowledge both in width and depth and attitude with wider vision. The learning will reduce the repetition of subject contents. The learners will learn from real experience which combines knowledge, moral, value, desirable characteristics and positive attitude in order to increase their potentials to learn more about life skills. The learners will be able to bring the knowledge into practice appropriately and efficiently in their real lives. The integrated learning will promote variety methods of learning with leaner-centered approach, thinking process, the management of a facing situation, the application of knowledge and the use of several skills in problemsolving (Khammani, 2002). The learning according to the Theory of Multiple Intelligences involves the development of learner characteristics to achieve the present educational philosophy, i.e., smart, good and happy. Teachers, therefore have to investigate the potentials of individual students (Department of Curriculum and Instruction Development, 2002). The concept of multiple intelligences learning can respond the individual differences involving the relationship between brain and learning. This type of learning will identify different kinds of genius of the individuals, the intellectual variety and the dimensions of brain functions. These features are together called multiple intelligences. Howard Gardner proposed an idea to improve the highest potential of a leaner by classifying prominent intelligences or talents of individual difference into 8 areas (Kotbantao, 2005). They are linguistic intelligence, logicalmathematical intelligence, musical intelligence, visualspatial intelligence, bodily-kinesthetic intelligence, interpersonal intelligence, intrapersonal intelligence and naturalist intelligence. The intelligences and talents within the individuals are different. The appropriate promotion and development for learners will create genius which is considered to be essential basis for providing the learners with smart, good and happy characteristics.

According the urgent need for solving the environmental problems, it is important to utilize the environmental education process as a tool to solve the problems. Therefore, the multiple intelligences integrated learning has been used to provide the learners with knowledge, attitude and awareness about environmental conservation. The researcher as an educator whose duty 
is to provide knowledge to university students then has been strongly interested in searching for a suitable learning method of the environment. This intention can be used as a guideline for developing learning and teaching innovations emphasizing on providing people the knowledge, attitude and awareness about value of the environment for future sustainable development.

\section{Objectives:}

- To investigate the effectiveness index of multiple intelligences integrated learning plans

- To study and compare the knowledge, attitude and awareness about environmental conservation of students before and after the use of multiple intelligences integrated learning and the normal learning

- To study and compare the knowledge, attitude and awareness about environmental conservation of students classified by genders, programs of study and learning methods

\section{MATERIALS AND METHODS}

\section{Research instruments}

Sample: The sample used in this research was 60 male and female full time bachelor degree students in Geography, Social Science and Thai Programs of all years of study of Chiang Mai Rajabhat University who enrolled to study the course of Humans and Sustainable Environment. They were divided into 2 groups; experimental and controlled groups and selected by cluster random sampling by drawing.

Instruments: The instruments used in the study were as follows:

- Two, 2 sets of learning plans were used. They were multiple intelligences integrated learning plans and normal learning plans. The first set of multiple intelligences integrated learning plans was used with the experimental group. The second set of normal learning plans was used with the controlled group

- A test of knowledge about environmental conservation was used with 40 items, the difficulty between 0.20 and 0.80 , the discrimination between 0.27 and 62 and the reliability for the whole study of 0.87

- A test of attitude toward environmental conservation was used with 20 items

- A test of awareness toward environmental conservation was used with 70 items of 5-rating scale, the discrimination between 0.20 and 91 and the reliability for the whole study of 0.98
Procedures: The students were divided into 2 groups; experimental group (with the use of multiple intelligences integrated learning) and controlled groups (with the use of normal learning).

Pretest was carried out to test the knowledge, attitude and awareness about environmental conservation of students before the use of multiple intelligences integrated learning and normal learning.

Two groups of student were taught with the same contents and within the same duration of time. The students of experimental group were taught by using multiple intelligences integrated learning while the students of controlled group were taught by using normal learning.

Post-test which was the same study as pre-test was used again after the use of both types of teaching to test the knowledge, attitude and awareness about environmental conservation of students of those two groups. This post-test was carried in order to collect the scores after teaching and then the scores were compared with the scores before the teaching.

Data processing and analysis: The test of knowledge of environmental conservation:

- The answers from the tests of knowledge about environmental conservation before and after the learning were marked

- The scores obtained from 1 were analyzed for means and standard deviations

- The means and standard deviations of scores from 2 were compared to find out about the differences of the scores before and after the use of multiple intelligences integrated learning and normal learning

The test of attitude toward environmental conservation:

- The answers from the test of attitude toward environmental conservation were examined for their completion

- The answers were marked according to the criteria

- The scores obtained from 2 were analyzed for percentages, means and standard deviations. The means were then interpreted according to the criteria

- The means of scores before and after the use of multiple intelligences integrated learning and normal learning were compared for their differences

The test of awareness about environmental conservation:

- All returned answers from the test of awareness about environmental conservation were examined for their completion 
- The answers were marked according to the criteria. The scores obtained were then analyzed for percentages, means and standard deviations

- The means of scores before and after the use of multiple intelligences integrated learning and normal learning were compared for their differences

The analyses of scores: The scores of knowledge, attitude and awareness about environmental conservation were statistically analyzed and tested according to objectives of the study.

\section{RESULTS AND DISCUSSION}

Part 1: The effectiveness index of multiple intelligences integrated learning plans was 0.7463 . This index indicated that the learning progress of students with the plans was at $74.63 \%$. The effectiveness index of normal learning plans was 0.5979 . This index indicated that the learning progress of students with the plans was at $59.79 \%$.

Part 2: The comparison of knowledge, attitude and awareness about the environmental conservation of students before and after the use of multiple intelligences integrated learning and normal learning is shown in Table 1.

From Table 1, it was found that the average score of knowledge about the environmental conservation of students in general before the use of multiple intelligences integrated learning was at $47.57 \%$ of the full score while the average score after the learning was at 87.82 of the full score. The average score of knowledge about the environmental conservation of students in general before the use of normal learning was at $51 \%$ of the full score while the average score after the learning was at 80.75 of the full score.

The levels of knowledge about environmental conservation of the students in general after the use of multiple intelligences integrated learning and of normal learning were higher than those of before the learning with statistically significance at the level of 0.05 . The attitude toward environmental conservation of students in general before the use of multiple intelligences integrated learning was at the middle level and after the learning was at the high level. The attitude toward environmental conservation of students in general before and after the use of normal learning was at the middle level. The attitude toward environmental conservation of students in general after the use of multiple intelligences integrated learning and normal learning was higher than that of before the learning with statistically significance at the level of 0.05 .

The awareness toward environmental conservation of students in general before the use of multiple intelligences integrated learning was at the middle level and after the learning was at the high level. The awareness toward environmental conservation in general and individual stages of students in general before the use of normal learning was at the middle level and after the learning was at the high level. The awareness toward environmental conservation of students in general after the use of multiple intelligences integrated learning and normal learning was higher than that of before the learning with statistically significance at the level of 0.05 .

Part 3: The comparison of knowledge, attitude and awareness about the environmental conservation of students with different genders, programs of study and learning methods (Three-way MANOVA) after the learning is shown in Table 2.

From Table 2, it was found that the knowledge, attitude and awareness about the environmental conservation of students with different genders and programs of study after the learning were not different. The knowledge, attitude and awareness about the environmental conservation of students after using two different learning methods were different with statistically significance at the level of 0.05 (Table 3). The knowledge,

Table 1: The comparison of knowledge, attitude and awareness about the environmental conservation of students before and after the use of multiple intelligences integrated learning and normal learning

\begin{tabular}{|c|c|c|c|c|c|c|c|c|c|c|c|c|}
\hline \multirow[b]{3}{*}{ Learning results } & \multicolumn{6}{|c|}{ Multiple intelligences integrated learning } & \multicolumn{6}{|c|}{ Normal learning } \\
\hline & \multicolumn{2}{|c|}{ Before leaming } & \multicolumn{2}{|c|}{ After learning } & \multirow[b]{2}{*}{$\mathrm{t}$} & \multirow[b]{2}{*}{$\mathrm{p}$-values } & \multicolumn{2}{|c|}{ Before learning } & \multicolumn{2}{|c|}{ After learning } & \multirow[b]{2}{*}{$\mathrm{t}$} & \multirow[b]{2}{*}{ p-values } \\
\hline & $\overline{\mathrm{X}}$ & $\mathrm{SD}$ & $\overline{\mathrm{X}}$ & $\mathrm{SD}$ & & & $\overline{\mathrm{X}}$ & $\mathrm{SD}$ & $\overline{\mathrm{X}}$ & $\mathrm{SD}$ & & \\
\hline $\begin{array}{l}\text { Knowledge about the } \\
\text { environmental conservation }\end{array}$ & $\begin{array}{l}19.03 \\
(47.57)^{1}\end{array}$ & 2.09 & $\begin{array}{l}35.13 \\
(87.82)^{1}\end{array}$ & 1.25 & -36.347 & $0.000^{*}$ & $\begin{array}{l}20.40 \\
(51.00)^{1}\end{array}$ & 1.89 & $\begin{array}{l}32.30 \\
(80.75)^{1}\end{array}$ & 2.00 & -13.802 & $0.000^{*}$ \\
\hline $\begin{array}{l}\text { Attitude toward the } \\
\text { environmental conservation }\end{array}$ & $3.11^{1}$ & 1.68 & $3.62^{2}$ & 0.14 & -21.153 & $0.000^{*}$ & $3.10^{1}$ & 0.17 & $3.35^{1}$ & 0.14 & -8.355 & $0.000^{*}$ \\
\hline Awareness toward the & $3.46^{1}$ & 0.09 & $4.19^{2}$ & 0.22 & -37.073 & $0.000^{*}$ & $3.15^{1}$ & 0.07 & $3.52^{2}$ & 0.16 & -22.759 & $0.000^{*}$ \\
\hline
\end{tabular}

environmental conservation

*With statistical significance at the level of 0.05 ; Knowledge about the environmental conservation; ${ }^{1}$ In parenthesis refers to percentage. Attitude toward the environmental conservation: ${ }^{1}$ Refers to the middle level $(\overline{\mathrm{X}}=2.51-3.50)$ and ${ }^{2}$ Refers to the high level $(\overline{\mathrm{X}}=3.51-4.50)$. Awareness toward the environmental conservation: ${ }^{1}$ Refers to the middle level $(\overline{\mathrm{X}}=2.51-3.50)$ and 2 refers to the high level $(\overline{\mathrm{X}}=3.51-4.50)$ 
The Soc. Sci., 7 (2): 308-315, 2012

Table 2: The comparison of knowledge, attitude and awareness about the environmental conservation of students with different genders, programs of study and learning methods after the learning

\begin{tabular}{llcccc}
\hline Source of variance & Test statistics & F & Hypothesis df & Error df & p-values \\
\hline Genders & Pillai's trace & 2.004 & 3.000 & 46.000 & 0.127 \\
& Wilks' lambda & 2.004 & 3.000 & 46.000 & 0.127 \\
& Hotelling's trace & 2.004 & 3.000 & 46.000 & 0.127 \\
Programs of study & Roy's largest root & 2.004 & 3.000 & 46.000 & 0.127 \\
& Pillai's trace & 0.733 & 6.000 & 94.000 & 0.624 \\
& Wilks' lambda & 0.728 & 6.000 & 9.000 & 0.628 \\
& Hotelling's trace & 0.723 & 6.000 & 47.000 & 0.632 \\
Learning methods & Roy's largest root & 1.352 & 3.000 & 36.000 & 0.269 \\
& Pillai's trace & 130.989 & 3.000 & 46.000 & $0.000^{*}$ \\
& Wilks' Lambda & 130.989 & 3.000 & 4.000 & $0.000^{*}$ \\
Genders *programs of study & Hotelling's trace & 130.989 & 3.000 & 0.000 & $0.000^{*}$ \\
*leaming methods & Roy's largest root & 130.989 & 3.000 & 144.000 & 0.140 \\
& Pillai's trace & 1.376 & 21.000 & 132.637 & 0.137 \\
& Wilks' Lambda & 1.385 & 21.000 & 134.000 & 0.134 \\
& Hotelling's trace & 1.389 & 21.000 & 48.000 & $0.012^{*}$ \\
\hline
\end{tabular}

*With statistically significance at the level of 0.05

Table 3: The comparison of knowledge, attitude and awareness about the environmental conservation of students with different learning methods (Univariate test)

\begin{tabular}{lrrrrr}
\hline Learning results (SOV) & SS & df & MS & F & p-values \\
\hline Knowledge about the environmental conservation & & \\
Contrast & 147.267 & 1 & 147.267 & 63.997 & $0.000^{*}$ \\
Error & 133.467 & 58 & 2.301 & & \\
Attitude toward the environmental conservation & & \\
Contrast & 1.092 & 1 & 1.092 & 50.585 & $0.000^{*}$ \\
Error & 1.252 & 58 & 0.022 & & \\
Awareness toward the environmental conservation & & \\
Contrast & 6.306 & 1 & 6.306 & 191.877 & $0.000^{*}$ \\
Error & 1.906 & 58 & 0.033 & & \\
\hline *With
\end{tabular}

*With statistical significance at the level of 0.05

Table 4: Means and standard deviations of knowledge, attitude and awareness about the environmental conservation of students with different learning methods (Univariate test)

\begin{tabular}{lcccc}
\hline & $\begin{array}{l}\text { Multiple intelligences } \\
\text { integrated learning }\end{array}$ & Normal learning \\
& $\overline{\mathrm{X}}$ & $\mathrm{SD}$ & $\overline{\mathrm{x}}$ & $\mathrm{SD}$ \\
\hline $\begin{array}{l}\text { Learning results } \\
\text { Knowledge about the }\end{array}$ & 35.13 & 1.25 & 32.00 & 1.74 \\
$\begin{array}{l}\text { environmental conservation } \\
\text { Attitude toward the } \\
\text { environmental conservation }\end{array}$ & 3.62 & 0.14 & 3.35 & 0.14 \\
$\begin{array}{l}\text { Awareness toward the } \\
\text { environmental conservation }\end{array}$ & 4.19 & 0.22 & 3.54 & 0.12 \\
\hline
\end{tabular}

attitude and awareness about the environmental conservation of the students with multiple intelligences integrated learning were higher than those of students with normal learning with statistically significance (Table 4). However, there was no relationship among genders, programs of study and learning methods with their knowledge, attitude and awareness about the environmental conservation.

The effectiveness indices of the multiple intelligences integrated learning plans and the normal learning plans were 0.7463 and 0.5979 , respectively. These findings indicated that the learning progresses of students were at 74.63 and $59.79 \%$, respectively. The knowledge, attitude and awareness about the environmental conservation of the students in general after the use of multiple intelligences integrated learning and normal learning were higher than those of before the learning with statistically significance at the level of 0.05 . The knowledge, attitude and awareness about environmental conservation of the students with different genders and programs of study after the learning were not different. The knowledge, attitude and awareness about environmental conservation of the students with different learning methods were different with statistical significance at a level of 0.05 . The knowledge, attitude and awareness about the environmental conservation of the students with multiple intelligences integrated learning were higher than those of students with normal learning with statistically significance. There was no relationship among genders, programs of study and learning methods with the knowledge, attitude and awareness about environmental conservation.

The effectiveness index of multiple intelligences integrated learning plans was 0.7463 . This index indicated that the learning progress of students was at $74.63 \%$. The reason for this finding is that from the use of multiple intelligences integrated learning which focuses on the areas of linguistic, visual-spatial, logical-mathematical and naturalist intelligences. This type of learning will provide students with knowledge of many subjects integrated into a new knowledge. The students eventually are able to relate the old knowledge with the new one as a holistic knowledge or concepts of such topics. This inner holistic knowledge can be used with problem solving in their daily life, especially the environmental problems. These reasons are consistent with the study of Tasana who mentioned about the advantages of an integrated learning which facilitates the learners to understand the contents in a holistic way. The learners can quickly see a relationship of the information. This form of learning will motivate and 
provide them with knowledge both in width and depth and attitude with wider vision. The learning will reduce the repetition of subject contents. The learners will learn from real experience which combines knowledge, moral, value, desirable characteristics and positive attitude in order to increase their potentials to learn more about life skills. The learners will be able to bring the knowledge into practice appropriately and efficiently in their real lives. The integrated learning will promote a variety of learning forms or methods with leaner-centered approach, thinking process, the management of a facing situation, the application of knowledge and the use of several skills in problem-solving.

Furthermore, this learning method will promote the democracy, the respect of other rights and the consideration of opinions and benefits of the majority. It helps solve the problem concerning the lack of instructors in each course. The learners will understand their social problems well with board consideration by using several related knowledge. The learning will therefore promote the learners skills and ability to solve problems and to carry out researches. This can increase the value of education as well as teaching. The teaching helps promote the essential skills, correct concepts, development of desirable characteristics and ability to work and control emotion of the learners.

The findings are in accordance with the research of Sirithammajak (2009) who investigated the effects of 5-E learning cycle approach with multiple intelligences and learning by the teachers' handbooks on the learning achievement, critical thinking and awareness toward environmental conservation of Mathayomsuksa (Grade 9) students. The main objectives of this research were to study and compare the learning outcomes of the 5-E learning cycle approach with multiple intelligences and the learning by the teachers' handbooks. The research results revealed that the effectiveness index of $5-\mathrm{E}$ learning cycle approach with multiple intelligences plans was at 0.7925 . This indicated that the learning progress of students was at $79.25 \%$.

The knowledge, attitude and awareness about the environmental conservation of the students in general after the use of multiple intelligences integrated learning were higher than those of before the learning with statistically significance at the level of 0.05 . The reason of this finding might be because the multiple intelligences integrated learning is a learning method that allows the learners to link the knowledge from their prior experience with the new knowledge of multi disciplinary contents. This agrees with Nuangchalerm (2004) who stated that the behaviors expressed by people are mostly come from the learning. However, the learning is not limited only the matter of skills or intelligence development, it also covers the solving of emotional problems, motivations, social behaviors and personality adjustment. The use of multiple intelligences with the learning is necessary to rely on the prior experience which is the basis for the intelligence development in specific areas of the individuals and for the exercises to improve weak intelligences to be stronger. The change of behavior for learning according to the theory of multiple intelligences does therefore not come from only the prior experience but it is also the result from training, practicing and doing.

From the belief that individual people will have different abilities or talents, the methods for individual development are therefore different, too. Different environment will clearly affect on the promotion of different abilities (Integrated Administration Committee, 2002). This findings are similar to the study of Dillihunt (2004) who investigated the effects of teaching with theory of multiple intelligences and teaching with lecture ro direct method on learning achievement in Mathematics involvement in activities and motivation of $3 \mathrm{rd}$ and 5 th grade students.

Regarding the results, it was found that the post-test scores of students with the use of multiple intelligences teaching were higher than those of the students with teaching of direct method. The results of the study were in line with the studies of Lawson (2001) and Techakup (2001) who stated that the activities using a variety of intellectual procedures according to the theory of multiple intelligence will provide the learners with opportunity to practice several areas of intelligence. Each area of intelligences will be related to each other and this promotes the appropriate development of advanced intellectual abilities such as critical thinking, awareness toward environmental conservation and learning achievement.

The knowledge, attitude and awareness about the environmental conservation of the students after the use of multiple intelligences integrated learning were generally higher than those of students with normal learning with statistically significance. These findings were consistent to Ministry of Education (2002) who proposed about the integrated features and the management of learning methods of each range of study (4 years for each range). The learning methods should emphasize on authentic learning and teaching, learning with the environment from actual practice and holistic integration. These actions will be used to determine the learner-centered learning objective through the learning process within the same contents or learning groups or from different groups which are integrated in learning and teaching. In this research, the integrated learning method with single teacher was applied. This type of teaching will provide 
learning by linking the several learning contents with topics which relate to life or others as determined. The learning method was linked with the contents and learning processes of several areas of study, e.g., Geography, Environmental Science, Environmental Education, Environmental Management, Environmental Technology, Calculation, Mathematics, Thai and Critical Thinking. Knowledge from these areas will facilitate the learners to use skills and learning process in searching for knowledge of the topics as determined. This principle conformed to the intellectual procedures (Welch, 1981), the Theory of Intellectual Development of Piaget (Barman and Kotar, 1989) and the framework for organizing activities in each stage (Lawson, 2001). Together with activities for the development of several intellectual abilities according to the multiple intelligences, each area of intelligences is able to have mutual relationship (Techakup, 2001). These activities with multiple intelligences learning will promote the students with higher levels of knowledge progress, attitude development and awareness toward the environmental conservation than those of students with normal learning.

\section{CONCLUSION}

In this study, the multiple intelligences integrated learning has efficiency and effectiveness and is appropriate to be used to promote the knowledge, attitude and awareness about environmental conservation of the learners. Teachers should be encouraged to bring this learning method into practice with their teaching about the environment.

\section{RECOMMENDATIONS}

The instructors of environmental education should bring the multiple intelligences integrated learning into practice in their own classes. This type of learning can be used with all levels of target groups. It will help to develop the learners' intelligences in all domains and also promote their awareness toward the environmental conservation. The learners with the use of multiple intelligences integrated learning can develop their intelligence in all domains. These domains include cognitive domain (i.e., knowledge and understanding), affective domain (i.e., feeling and awareness) and psychomotor domain (i.e., skills and behaviors).

They all need the promotion of their sustainable development. Regarding to this integrated learning, the learners will study things of their own needs and interests leading to the development of knowledge, attitude and awareness about the environmental conservation. There should be further studies about the use of multiple intelligence integrated learning with other topics or courses. These studies will help expand the area of learning methods and achieve more goals of education. There should be further studies about the comparisons of this integrated learning with other teaching methods. These studies will promote the development of teaching methods and the search for teaching methods suitable for the target groups of environmental education.

\section{ACKNOWLEDGEMENTS}

Special thank is extended to my supervisor, Dr. Prayoon Wongchantra (Chairman of the Doctoral Dissertation Committee), for his continual support, guidance and director throughout this study, to Assistant Professor Dr. Prasat Neungchalerm (Member of the Doctoral Dissertation Committee), for his useful advice and support.

\section{REFERENCES}

Barman, C.R. and M. Kotar, 1989. The learning cycle. Sci. Children, 26: 30-32.

Chunkao, K., 1993. Environmental Education. Aksornsayam Publishing, Bangkok.

Department of Curriculum and Instruction Development, 2002. Teachers handbook for learning materials development. Bangkok: Express Transportation Organization of Thailand.

Dillihunt, M.L., 2004. The effects of multiple intelligences and direct instruction on third and fifth grade student achievement, task engagement, student motivation and teacher efficacy. Masters Abstr. Int., 64: 4354-4354.

Integrated Administration Committee, 2002. Environment, Technology and Life. 6th Edn., Kasetsart University, Bangkok, Thailand.

Khammani, T., 2002. Science of Teaching: Knowledge for an Efficient Management of Learning Process. Dansutha Printing, Bangkok.

Kotbantao, S., 2005. Theory of Multiple Intelligences. Institute for Development of Educational Administrators, Nakhon Pathom, Thailand.

Lawson, A.E., 2001. Using the learning cycle to teach biology concepts and reasoning patterns. J. Biol. Educ., 354: 165-169.

Ministry of Education, 2002. Basic Education Curriculum B.E. 2544. 2nd Edn., Express Transportation Organization of Thailand, Bangkok. 
Nuangchalerm, P., 2004. Multiple intelligences: Intelligent approach for learning. J. Learn. Teach. Innovat, Vol. 1.

Sirithammajak, S., 2009. The effects of 5-E learning cycle approach with multiple intelligences and learning by the teachers' handbooks on the learning achievement, critical thinking and awareness toward environmental conservation of mathayomsuksa 3 students. Ph.D. Thesis, Mahasarakham University, Mahasarakham.
Techakup, Y., 2001. The Development of Learning Potentials According to Multiple Intelligences Model for Learning in Thai Society Context. Office of National Education Commission, Bangkok.

Veerawattananon, V., 2003. Environmental Education. 3rd Edn., Odeon Store Printing House, Bangkok, Thailand.

Welch, W.W., 1981. Inquiry in School Science. In: What Research Says to the Science Teachers, Norris, C.H. and R.E. Yager (Eds.). National Science Teachers Association, Washington, DC., pp: 53-64. 